\title{
Research on Venture Capital Policy Making Based on Options Pricing Theory
}

\author{
Jingjing Feng \\ Xi'an Peihua University, Xi'an, 710123, China
}

Keywords: Venture capital, Options pricing, Policy making

\begin{abstract}
Uncertain pricing is one core of financial mathematics study, it involves the theories of modern finance such as asset pricing theory, investment combination theory and risk management theories, as well as stochastic analyzing and optimizing theory of modern mathematics. The paper, with the help of option pricing method, introduces barter option pricing formula and compares and analyzes the similarities and differences between NPV method and barter option pricing method to provide guidance for the investors to make correct decisions.
\end{abstract}

\section{Introduction}

Option is the right to buy or sell something at a fixed price within a certain period. It is a kind of financial derivative contract, also called option. We call the purchase of this right a call option, and sell this right called a put option. The option gives the holder the power, not the obligation. To obtain the right, the purchaser must pay a certain fee to the seller, which is called the option fee or option price. The execution price is also known as the strike price, the option buyer under option contract execution in the exercise of their rights, the price, the price of most prior to finalize, but some only agreed method for determining price. Obviously, once the execution price is determined, the option buyer must decide whether to exercise the right according to the relative price of the executed asset and the underlying asset. The expiration date of the option is called expiration date or expiration date. Option buyers can only make their rights within the time stipulated in the contract. Once the period exceeds the limit, it means voluntary waiver of rights. The option can be divided into European option and American option according to the time division of option execution by option buyer. The European option only on the maturity date of the option to perform option; and the American option allows the option buyer at any point in time before the date of execution options. Any kind of transaction has both buyer and seller, and option transaction is no exception. The option purchaser, also known as a holder or option holder, has the right to purchase or sell a certain amount of underlying assets after the payment of the option fee. He can also do without this obligation without any obligation, which is the fundamental difference between options and Futures and forward contracts. On the contrary, the seller of option is also called option short. After collecting the option fee, he must undertake the obligation stipulated in the option contract without any right.

\section{Basic Options Pricing Methods}

Binary-tree Model Based on Bayesian. Two binary tree option pricing model by Cox, Ross and Rubenstein was first proposed in 1979, has become one of the most basic financial option pricing method, the utility model has the advantages of simple and intuitive, do not need too much knowledge of mathematics can be used. But with further research, the binomial model is not only used as an auxiliary tool to solve the Black Sholes model, it has become a complex option (variation options such as American option and nonstandard) basic means of pricing model.

The single step two tree model assumes a dividend free stock, the current $\mathrm{t}$ stock price is $\mathrm{S}$, the value of an option based on the stock is $\mathrm{f}$, and the option is valid for T. During this period, the stock 
price rises to $\mathrm{Su}$, or drops to $\mathrm{Sd}(\mathrm{u}>1, \mathrm{~d}<1)$. When the stock price rises to $\mathrm{Su}$, the option's return is $\mathrm{Fu}$, and if the stock price falls to Sd, the option income is fd. Option pricing can be carried out in a risk neutral world, and the option pricing can also be applied in the two-branch tree model by applying the risk neutral pricing principle. It is assumed that the rising probability of stocks in the risk neutral world is $p$, because the present value of the stock future value discounted at the risk-free interest rate must be equal to the current price of the stock, so the probability can be obtained by the lower form:

$$
S=e^{-r(T-t)}[\operatorname{Sup}+\operatorname{Sd}(1-p)]
$$

When the risk neutral probability is known, the option price can be obtained by the lower form:

$$
f=e^{-r T}\left[p f_{u}+(1-p) f_{d}\right]
$$

Based on the option pricing formula of single period call option, the two tree option pricing formula of two call options can be obtained, and then extended to binomial option pricing formula of $\mathrm{N}$ call option. Consider buying call options $\mathrm{n}$, the current stock price is $\mathrm{S}$, the probability of $\mathrm{P}$, while the stock in each period the rise or fall of 1-p, and $\mathrm{u}$, D values are the same, each stock price has two possible, so, to $\mathrm{N}$ at the end of all possible values for the stock price, $\mathrm{i}=0,1, \ldots \mathrm{N}$, according to the idea of deducing two period model, starting from phase n, we can get the two fork tree pricing formula of $\mathrm{N}$ period look options:

$$
c=e^{-n r \Delta t} \sum_{i=0}^{n}\left[\frac{n !}{i !(n-i) !} p^{i}(1-p)^{n-1} \max \left(S u^{i} d^{n-i}-X, 0\right)\right]
$$

The two-tree option pricing model is a discrete way to deal with the price, so the option contract, this model can consider the dividend. Moreover, when the tree structure is completed, it is easy to predict the price of the previous node and calculate the theoretical value of any node in the price tree. At each node, the value of continued holding and immediate execution can be compared, so that an optimal value can be selected. Not only can we get a reasonable price for each point, we can know the optimal option execution time. Therefore, the two-tree option pricing model can also be used in the calculation of American options. To make the data calculated by the two-tree option pricing model more accurate, it will have to take the larger value of $n$. However, when $n$ increases, the need to increase the calculation steps show a geometric progression. As $\mathrm{n}$ becomes larger and larger, and finally tends to infinity, the two-branch tree model and Black one Scholes option pricing model are the same. When the Black one Scholes option pricing model is limited or has a big error with the actual situation, the two-fork tree model is used to make the option pricing better.

Monte Carlo Simulation. Monte Carlo simulation method is also a numerical method, which can be used to estimate European derivatives. This method can deal with complicated situations and the relative efficiency of calculation is high. It derives the option value at the future time from the option value at the initial time, and is only used for the calculation of European option. The basic idea is: the simulation method of Monte Carlo distribution function assumed known underlying asset price, then the expiry date option is divided into several small-time intervals, with the help of a computer, can simulate each time interval, the fluctuation of stock price and the stock price of a possible path from random sampling distribution in the sample, so it can calculate the final value of the option. This result can be considered as a random sample of all possible final value sets, and another random sample can be obtained with another path of this variable. More random samples can be obtained by using more sample paths. Thus, we can get the set of $\mathrm{T}$ time option price, and make a simple arithmetic average for thousands of random samples, then we can get the expected return of $\mathrm{T}$ time option. According to the principle of no arbitrage pricing, the $\mathrm{Xr}$ of the future $\mathrm{T}$ option is discounted at the risk-free interest rate, and the price of the option now can be obtained:

$$
P=e^{-r T} E\left(X_{T}\right)
$$

The Monte Carlo simulation method is generally used to analyze the standard deviation of the underlying stock as a random variable, and the path of the stock price and standard deviation is simulated simultaneously. The value of standard deviation at any time determines the probability distribution of the stock price to be sampled. The advantages of Monte Carlo method is that it can be used for the expected rate of return and volatility of the underlying asset ratio function is more 
complex, but also increase the simulation time with the number of variables of the linear growth, its operation is more efficient. However, the limitation of this method is that it can only be applied to the valuation of European options, but not to American options that can execute contracts ahead of time. And the accuracy of the Monte Carlo simulation method depends on the number of simulation operations. Monte Carlo simulation can be combined with two tree graph method to make option pricing. When the tree graph is constructed, we can extract the path samples randomly from the tree graph. This is different from the back after the nephew of $\mathrm{L}$ is not pushed, but along the tree pushed back. The basic method is as follows: in the first node, we take a random number between 0 and 1 , if the random number is less than $\mathrm{P}$, we choose the ascending branch, and vice versa choose the descending branch. When we arrive at the next node, we repeat the process until we arrive at the end of the tree graph, and then we can calculate the option profit and loss value of the selected path, so we complete the first simulation. Repeat the whole step and simulate several times. We take all these profit and loss values at discounted risk-free rates and take the average value, which is the value of the option price.

\section{Advantages of Applications of Options Pricing Theory in Venture Capital Policy}

To the exit of venture capital decision-making has the following advantages: first, using option pricing method of option pricing does not need to know the cash flow each year investment period; second, the option pricing formula is obtained by using the risk neutral pricing method, so do not have the so-called risk adjustment, which also provide a more reasonable and effective method for hi tech enterprises lack of historical data, but also to avoid the risk coefficient is adjusted according to the results of the assessment of enterprises lack of similar enterprises can refer to the embarrassment. These two advantages make option pricing method more scientific and easier to handle than venture capital evaluation method based on net present value method and capital asset pricing model. The option pricing theory is introduced into the high-tech venture enterprise investment decision-making, reflects the enterprise's future investment plans, companies can develop according to market conditions and time selection, and option evaluation method reflects the change of technology and market risk, to better reflect the characteristics of high-tech venture enterprise value. Through the research on the investment risk, investment risk can be found with the option character, the risk of corporate venture capitalists on investment as a purchase option, if successful will reap huge gains, even if the failure of the biggest loss is investment in venture capital. Venture capitalists venture to put some venture capital to have a share, but the purpose is not to have the enterprise, but to sell their share in the risk of corporate value added to get investment income. The venture capitalists buy a put option with the invested capital as the option. It gives investors the right to sell their shares at a certain price.

\section{Procedures of Applications of Options Pricing Theory in Venture Capital Policy}

Using option pricing method to evaluate the feasibility of a venture capital project exit generally requires the following steps:

(1) To know the T-t. The C 'investment, project investment period

(2) The underlying asset value (S). Through the Vc firm and venture business negotiations, determine the Vc firm investment for venture enterprises in shares, and through the analysis and calculation of the enterprise value of the market price of the shares of $\mathrm{S}$.

(3) To estimate the period of investment in the risk-free interest rate rf, common practice is to take 90 days of short-term Treasury yields as the risk-free interest rate.

(4) The calculation of annual investment rate of return standard difference. Due to an investment in venture enterprises is phased into a stage of development, namely a fund to invest in venture enterprises, internal management and external environment risk at this stage in the development of enterprises is relatively stable and can be calculated in each period the annual rate of return of the standard difference using the ARCH model will be *, the arithmetic mean value as the return period 
of investment. The standard deviation can also use the following two methods: the probability of obtaining the standard deviation according to different market conditions appear different, were calculated and the present value of cash flow in each case, and then calculate the value of the variance of their changes; the average option changes. The reference of Listed Companies in the same industry or industry value depends on the cash flow, the more changes, namely, the greater the difference value, The higher the value. This also shows that the stability of the industry value option than the option value. The project technology, competition, and market fast changing environments

(5) The Vc firm according to the capital market investment returns, and fully consider the investment objectives identified risk investment risk premium based on the investment after the expiration of their expected risk benefit value of $\mathrm{P}$.

(6) The exercise price (X). Using the option formula B-S option pricing model and MATLAB function in the fzero calculation of the underlying asset price, execution time for $\mathrm{S} T$, European option price is $C$ 'executive price $X$. When venture capitalists decided to invest in high-tech venture enterprises have patent, patent option is executed, the investment of patent product cost is equal to the strike price, the implicit assumption that the cost of investment value unchanged, uncertainties associated with the product are reflected in the products and related cash flows in. It is worth noting that the Black-Scholes option pricing formula the underlying asset is not pay dividends, and venture capitalists to buy the underlying assets' venture enterprise shares, they are not entirely equivalent. But if the risk enterprises have been listed, no two the difference, can directly use stock options do not pay dividends or interest payment option known red pricing formula. If not listed, the risk can be assets profit rate as approximately obey the normal distribution, and the asset price obeys the lognormal distribution, can use the non-dividend paying stock option pricing formula.

(7) The comparison of $X$ and $P$. If $X>P$, indicates that the option value is underestimated, the investment is feasible, you don't have to quit; if $X=P$, shows that the option value is overvalued, the investment is not feasible, should quit.

\section{Conclusion}

Option pricing theory is an important part of finance, and its impact has gone far beyond the options trading field. Corporate decision makers use this theory as a powerful tool for investment decision analysis; securities analysts use this theory to estimate corporate bonds. Many economists have expanded it from wage negotiations to analysis of currency fluctuations. It has also been widely used in guarantee and insurance contracts.

\section{References}

[1] Bian Yuetang, Li Jinsheng, Xu Lu. Simulation and Evolution Model of Herding Behavior in Stock Market Based on the Strategy of Coordination Game in Network [J]. Chinese Journal of Management Science, 2017, 25(3): 20-29.

[2] Jiang Jinghua, Wan Jianping. Application of Option Pircing Theory on Venture Capital [J]. Journal of Wuhan University of Science and Engineering, 2008, 21(6): 108-111.

[3] Liu Dongrong, Li Xin. The Multi-stage Hybrid Option Pricing Model and Analysing on Risk Investment Decision- making [J]. Value Engineering, 2008(9): 153-156.

[4] Feng Jinghai, Zhu Junqiao. Nonlinear regression model and option analysis of real estate price [J]. Journal of Dalian University of Technology, 2017, 57(5): 545-550. 